\title{
Modeling Proton-Bound Methanol, Ammonia, and Amine Complexes of 12-Crown-4-Ether and Dimethoxyethane ("Glyme") Using Density Functional Theory
}

\author{
Dora Adötoledo, ${ }^{\dagger}$ Viktorya Aviyente, ${ }^{\dagger}$ Jan M. L. Martin,,$* \| l \mid$ and Chava Lifshitz ${ }^{*, \S, \perp}$ \\ Chemistry Department, Bogaziçi University, 80815, Bebek, Istanbul, Turkey, Department of Organic Chemistry, \\ Weizmann Institute of Science, Rehovot 76100, Israel, and Department of Physical Chemistry and the Farkas \\ Center for Light Induced Processes, The Hebrew University of Jerusalem, 91904, Jerusalem, Israel
}

Received: April 2, 1998; In Final Form: May 11, 1998

\begin{abstract}
The association reactions undergone by 12-crown-4-ether, $12 \mathrm{c} 4 \mathrm{H}^{+}$, with $\mathrm{NH}_{3}, \mathrm{CH}_{3} \mathrm{OH}, \mathrm{CH}_{3} \mathrm{NH}_{2},\left(\mathrm{CH}_{3}\right)_{2} \mathrm{NH}_{\text {, }}$ and $\left(\mathrm{CH}_{3}\right)_{3} \mathrm{~N}$ have been studied using the B3LYP density functional method and a variety of basis sets. For comparison purposes the insertion reactions for the same bases into protonated dimethoxyethane ("glyme"), $\mathrm{Gl} \cdot \mathrm{H}^{+}$, and protonated glyme dimer, $(\mathrm{Gl})_{2} \mathrm{H}^{+}$, have also been modeled. The B3LYP/aug-cc-pVDZ//B3LYP/ 4-21G(*) level of theory was found to be a particularly favorable compromise between accuracy and computational expense for the calculation of proton affinities of medium-sized species. The protonated glyme, $\mathrm{Gl} \cdot \mathrm{H}^{+}$, the protonated glyme dimer, $(\mathrm{Gl})_{2} \mathrm{H}^{+}$, and the protonated crown ether, $12 \mathrm{c} 4 \mathrm{H}^{+}$, form two internal hydrogen bonds with $\mathrm{NH}_{3}, \mathrm{CH}_{3} \mathrm{OH}, \mathrm{CH}_{3} \mathrm{NH}_{2}$, and $\left(\mathrm{CH}_{3}\right)_{2} \mathrm{NH}$, except for $(\mathrm{Gl})_{2} \mathrm{H}^{+} \cdot \mathrm{NH}_{3}$ which has four $\mathrm{O} \cdots \mathrm{H}$ bonds. In $\mathrm{Gl} \cdot \mathrm{NH}\left(\mathrm{CH}_{3}\right)_{3}{ }^{+}$, there is a single $\mathrm{O} \cdot \cdots \mathrm{H}$ bond and the protons of the methyl groups assist weakly in $\mathrm{O} \cdots \mathrm{HC}$ bonding. The insertion energy of methanol, ammonia, and the series of amines into $12 \mathrm{c} 4 \mathrm{H}^{+}$ increases with increasing proton affinity of the inserting base. A similar trend is observed for insertion into $(\mathrm{Gl})_{2} \mathrm{H}^{+}$. Trimethylamine does not follow the expected trend because it forms proton-bound complexes that have a single $\mathrm{O} \cdots \mathrm{HN}$ bond instead of two. The association energy of $\mathrm{CH}_{3} \mathrm{OH}_{2}{ }^{+}, \mathrm{NH}_{4}{ }^{+}$, etc., with $12 \mathrm{c} 4$ or $\mathrm{Gl}_{2}$ decreases with increasing proton affinity (of methanol, ammonia, etc.).
\end{abstract}

\section{Introduction}

Crown ethers have been of great interest since their first synthesis by Pedersen in $1967 .{ }^{1}$ The ability of polyethersglymes, crown ethers, and cryptands - to act as very effective complexing agents for cations is well established and represents a field of great chemical and biological significance. ${ }^{2}$

The importance of determining thermochemical properties for complexation of cations by polyethers, in the absence of solvent and counterions, has been pointed out. ${ }^{2 b, 3,4}$ Alkali metal-crown ether complexes have been studied by collision-induced dissociation threshold energy determinations employing guided ion beam experiments, ${ }^{2 \mathrm{~b}}$ while the specific species under study here have been studied using pulsed high-pressure mass spectrometry by Meot-Ner ${ }^{3}$ and by Kebarle and co-workers. ${ }^{4}$

The thermochemistry of internal hydrogen bonds and of multiple hydrogen bonding was estimated by comparisons between polyfunctional and analogous monofunctional ions. ${ }^{3}$ Polyethers, crown ethers, and glymes exhibit strong (30 kcal/ mol) internal hydrogen bonds, stabilizing the protonated species and increasing the PAs of the corresponding molecules. ${ }^{5,6}$ The hydrogen bonding of polyfunctional molecules with polyprotonic ions leads to multiply hydrogen bonded structures, which leads to stabilization of ion/molecule complexes $;{ }^{5}$ this was observed for ammonia-crown ether ${ }^{3}$ and methoxonium $\left(\mathrm{CH}_{3} \mathrm{OH}_{2}{ }^{+}\right)$crown ether complexes. ${ }^{4}$

\footnotetext{
† Bogaziçi University.

Weizmann Institute of Science.

$\S$ The Hebrew University of Jerusalem.

"Incumbent of the Helen and Milton A. Kimmelman Career Development Chair.

${ }^{\perp}$ Archie and Marjorie Sherman Professor of Chemistry.
}

Reactions of protonated 12-crown-4 ether $\left(12 \mathrm{c} 4 \mathrm{H}^{+}\right)$and its ammonium and methoxonium ion complexes with a series of base molecules were studied using a selected ion flow tube. ${ }^{7}$ Reaction efficiencies were observed to be enhanced for base molecules capable of forming multiple hydrogen bonded structures. The association reactions undergone by $12 \mathrm{c} 4 \mathrm{H}^{+}$with ammonia and methanol were viewed ${ }^{7}$ as insertion reactions analogous to reactions observed for alkyl-blocked dimers such as $\left(\mathrm{CH}_{3} \mathrm{CN}\right)_{2} \mathrm{H}^{+} .8-10$

In previous work, ${ }^{11}$ we have modeled the insertion reactions of ammonia, methylamine, dimethylamine, and methanol into proton-bound alkyl-blocked dimers of acetonitrile, $\left(\mathrm{CH}_{3} \mathrm{CN}\right)_{2} \mathrm{H}^{+}$, and acetone, $\left(\mathrm{CH}_{3} \mathrm{COCH}_{3}\right)_{2} \mathrm{H}^{+}$, using hybrid density functional methods and have explained their insertion mechanism. The purpose of the present work is to shed light on the reactions of bases with protonated glyme $\mathrm{Gl} \cdot \mathrm{H}^{+}$, protonated glyme dimer$(\mathrm{Gl}){ }_{2} \mathrm{H}^{+}$, and proton-bound 12-crown-4-ether $\left(12 \mathrm{c} 4 \mathrm{H}^{+}\right)$, with the same computational method.

\section{Methods}

All density functional calculations have been carried out using the Gaussian 94 package $^{12}$ running on a DEC Alpha TurboLaser 8400 at the Institute of Chemistry, Hebrew University; on a DEC Alpha 233/4 at the Chemistry Department, Bogaziçi University, and on DEC Alpha 500/500 and Silicon Graphics Origin 2000 computers at the Weizmann Institute of Science. Semiempirical calculations using the PM3 model ${ }^{13}$ were performed using Spartan. ${ }^{14}$

All density functional calculations employed the B3LYP (Becke three-parameter-Lee-Yang-Parr) exchange-correlation functional, ${ }^{15,16}$ which combines the Becke three-parameter 
TABLE 1: B3LYP Computed Dissociation Enthalpies at $298 \mathrm{~K}$ (kcal/mol) for the Different Complexes

\begin{tabular}{|c|c|c|c|}
\hline reaction & $4-21 G(*)$ & $\mathrm{VDZ} / / 4-21 \mathrm{G}(*)$ & AVDZ//4-21G(*) \\
\hline $\mathrm{GlH}^{+}(\mathbf{1 2}) \rightarrow \mathrm{Gl}(\mathbf{1 1})+\mathrm{H}^{+}(\mathrm{I})$ & 222.57 & 207.35 & 203.63 \\
\hline $\mathrm{Gl} \cdot \mathrm{CH}_{3} \mathrm{OH}_{2}{ }^{+}(\mathbf{1 3}) \rightarrow \mathrm{GlH}^{+}(\mathbf{1 2})+\mathrm{CH}_{3} \mathrm{OH}(\mathrm{II})$ & 35.61 & 26.34 & 20.92 \\
\hline $\mathrm{Gl} \cdot \mathrm{CH}_{3} \mathrm{OH}_{2}^{+}(\mathbf{1 3}) \rightarrow \mathrm{Gl}(\mathbf{1 1})+\mathrm{CH}_{3} \mathrm{OH}_{2}^{+}(\mathrm{III})$ & 64.35 & 49.54 & 45.44 \\
\hline $\mathrm{Gl} \cdot \mathrm{NH}_{4}^{+}(\mathbf{1 4}) \rightarrow \mathrm{GlH}^{+}(\mathbf{1 2})+\mathrm{NH}_{3}(\mathrm{IV})$ & 43.72 & 38.77 & 33.27 \\
\hline $\mathrm{Gl} \cdot \mathrm{NH}_{4}^{+}(\mathbf{1 4}) \rightarrow \mathrm{Gl}(\mathbf{1 1})+\mathrm{NH}_{4}^{+}(\mathrm{V})$ & 48.24 & 37.40 & 34.66 \\
\hline $\mathrm{Gl} \cdot \mathrm{NH}_{3} \mathrm{CH}_{3}{ }^{+}(\mathbf{1 5}) \rightarrow \mathrm{GlH}^{+}(\mathbf{1 2})+\mathrm{NH}_{2} \mathrm{CH}_{3}(\mathrm{VI})$ & 46.56 & 44.15 & 40.21 \\
\hline $\mathrm{Gl} \cdot \mathrm{NH}_{3} \mathrm{CH}_{3}{ }^{+}(\mathbf{1 5}) \rightarrow \mathrm{Gl}(\mathbf{1 1})+\mathrm{NH}_{3} \mathrm{CH}_{3}{ }^{+}(\mathrm{VII})$ & 45.99 & 33.18 & 29.97 \\
\hline $\mathrm{Gl} \cdot \mathrm{NH}_{2}\left(\mathrm{CH}_{3}\right)_{2}{ }^{+}(\mathbf{1 6}) \rightarrow \mathrm{GlH}^{+}(\mathbf{1 2})+\mathrm{NH}\left(\mathrm{CH}_{3}\right)_{2}(\mathrm{VIII})$ & 49.14 & 46.89 & 44.34 \\
\hline $\mathrm{Gl} \cdot \mathrm{NH}_{2}\left(\mathrm{CH}_{3}\right)_{2}{ }^{+}(\mathbf{1 6}) \rightarrow \mathrm{Gl}(\mathbf{1 1})+\mathrm{NH}_{2}\left(\mathrm{CH}_{3}\right)_{2}{ }^{+}(\mathrm{IX})$ & 40.07 & 30.30 & 26.94 \\
\hline $\mathrm{Gl} \cdot \mathrm{NH}\left(\mathrm{CH}_{3}\right)_{3}{ }^{+}(\mathbf{1 7}) \rightarrow \mathrm{GlH}^{+}(\mathbf{1 2})+\mathrm{N}\left(\mathrm{CH}_{3}\right)_{3}(\mathrm{X})$ & 46.88 & 43.59 & 42.10 \\
\hline $\mathrm{Gl} \cdot \mathrm{NH}\left(\mathrm{CH}_{3}\right)_{3}+(\mathbf{1 7}) \rightarrow \mathrm{Gl}(\mathbf{1 1})+\mathrm{NH}\left(\mathrm{CH}_{3}\right)_{3}+(\mathrm{XI})$ & 33.33 & 23.96 & 20.48 \\
\hline$(\mathrm{Gl})_{2} \mathrm{H}^{+}(\mathbf{1 8}) \rightarrow 2 \mathrm{Gl}(\mathbf{1 1})+\mathrm{H}^{+}(\mathrm{XII})$ & 256.67 & 234.23 & 226.98 \\
\hline$(\mathrm{Gl}){ }_{2} \mathrm{H}^{+}(\mathbf{1 8}) \rightarrow \mathrm{Gl}(\mathbf{1 1})+\mathrm{GlH}^{+}(\mathbf{1 2})(\mathrm{XIII})$ & 34.10 & 26.88 & 23.35 \\
\hline$(\mathrm{Gl})_{2} \mathrm{CH}_{3} \mathrm{OH}_{2}{ }^{+}(\mathbf{1 9}) \rightarrow(\mathrm{Gl})_{2} \mathrm{H}^{+}(\mathbf{1 8})+\mathrm{CH}_{3} \mathrm{OH}(\mathrm{XIV})$ & 26.05 & 19.11 & 13.71 \\
\hline$(\mathrm{Gl})_{2} \mathrm{CH}_{3} \mathrm{OH}_{2}{ }^{+}(\mathbf{1 9}) \rightarrow 2(\mathrm{Gl})+\mathrm{CH}_{3} \mathrm{OH}_{2}^{+}(\mathrm{XV})$ & 88.89 & 69.19 & 61.58 \\
\hline$(\mathrm{Gl})_{2} \mathrm{NH}_{4}^{+}(\mathbf{2 0}) \rightarrow(\mathrm{Gl})_{2} \mathrm{H}^{+}(\mathbf{1 8})+\mathrm{NH}_{3}(\mathrm{XVI})$ & 45.77 & 34.83 & 30.59 \\
\hline$(\mathrm{Gl})_{2} \mathrm{NH}_{4}{ }^{+}(\mathbf{2 0}) \rightarrow 2(\mathrm{Gl})+\mathrm{NH}_{4}{ }^{+}(\mathrm{XVII})$ & 84.39 & 60.34 & 55.33 \\
\hline $12 \mathrm{c} 4 \mathrm{H}^{+}(\mathbf{2 2}) \rightarrow 12 \mathrm{c} 4(\mathbf{2 1})+\mathrm{H}^{+}(\mathrm{XVIII})$ & 231.07 & 218.55 & 216.94 \\
\hline $12 \mathrm{c} 4 \mathrm{H}^{+} \cdot \mathrm{CH}_{3} \mathrm{OH}(\mathbf{2 3}) \rightarrow 12 \mathrm{c} 4 \mathrm{H}^{+}(\mathbf{2 2})+\mathrm{CH}_{3} \mathrm{OH}(\mathrm{XIX})$ & 35.79 & 27.18 & 20.04 \\
\hline $12 \mathrm{c} 4 \mathrm{H}^{+} \cdot \mathrm{CH}_{3} \mathrm{OH}(\mathbf{2 3}) \rightarrow 12 \mathrm{c} 4(\mathbf{2 1})+\mathrm{CH}_{3} \mathrm{OH}_{2}^{+}(\mathrm{XX})$ & 73.02 & 61.58 & 57.87 \\
\hline $12 \mathrm{c} 4 \mathrm{H}^{+} \cdot \mathrm{NH}_{3}(\mathbf{2 4}) \rightarrow 12 \mathrm{c} 4 \mathrm{H}^{+}(\mathbf{2 2})+\mathrm{NH}_{3}(\mathrm{XXI})$ & 45.67 & 39.62 & 33.13 \\
\hline $12 \mathrm{c} 4 \mathrm{H}^{+} \cdot \mathrm{NH}_{3}(\mathbf{2 4}) \rightarrow 12 \mathrm{c} 4(\mathbf{2 1})+\mathrm{NH}_{4}{ }^{+}(\mathrm{XXII})$ & 58.69 & 49.44 & 47.82 \\
\hline $12 \mathrm{c} 4 \mathrm{H}^{+} \cdot \mathrm{NH}_{2} \mathrm{CH}_{3}(\mathbf{2 5}) \rightarrow 12 \mathrm{c} 4 \mathrm{H}^{+}(\mathbf{2 2})+\mathrm{NH}_{2} \mathrm{CH}_{3}(\mathrm{XXIII})$ & 49.55 & 44.65 & 38.96 \\
\hline $12 \mathrm{c} 4 \mathrm{H}^{+} \cdot \mathrm{NH}_{2} \mathrm{CH}_{3}(\mathbf{2 5}) \rightarrow 12 \mathrm{c} 4(\mathbf{2 1})+\mathrm{NH}_{3} \mathrm{CH}_{3}^{+}(\mathrm{XXIV})$ & 57.48 & 44.87 & 42.03 \\
\hline $12 \mathrm{c} 4 \mathrm{H}^{+} \cdot \mathrm{NH}\left(\mathrm{CH}_{3}\right)_{2}(\mathbf{2 6}) \rightarrow 12 \mathrm{c} 4 \mathrm{H}^{+}(\mathbf{2 2})+\mathrm{NH}\left(\mathrm{CH}_{3}\right)_{2}(\mathrm{XXV})$ & 50.89 & 45.64 & 41.09 \\
\hline $12 \mathrm{c} 4 \mathrm{H}^{+} \cdot \mathrm{NH}\left(\mathrm{CH}_{3}\right)_{2}(\mathbf{2 6}) \rightarrow 12 \mathrm{c} 4(\mathbf{2 1})+\mathrm{NH}_{2}\left(\mathrm{CH}_{3}\right)_{2}{ }^{+}(\mathrm{XXVI})$ & 50.32 & 40.24 & 37.01 \\
\hline $12 \mathrm{c} 4 \mathrm{H}^{+} \cdot \mathrm{N}\left(\mathrm{CH}_{3}\right)_{3}(\mathbf{2 7}) \rightarrow 12 \mathrm{c} 4 \mathrm{H}^{+}(\mathbf{2 2})+\mathrm{N}\left(\mathrm{CH}_{3}\right)_{3}(\mathrm{XXVII})$ & 41.88 & 38.36 & 35.21 \\
\hline $12 \mathrm{c} 4 \mathrm{H}^{+} \cdot \mathrm{N}\left(\mathrm{CH}_{3}\right)_{3}(\mathbf{2 7}) \rightarrow 12 \mathrm{c} 4(\mathbf{2 1})+\mathrm{N}\left(\mathrm{CH}_{3}\right)_{3} \mathrm{H}^{+}(\mathrm{XXVIII})$ & 36.83 & 29.93 & 26.89 \\
\hline
\end{tabular}

hybrid exchange functional ${ }^{15}$ with the gradient-corrected correlation functional of Lee, Yang, and Parr. ${ }^{16}$ The excellent performance of this method has been noted previously for geometries and harmonic frequencies. ${ }^{17}$

Geometry optimizations and harmonic frequency calculations were carried out using the 4-21G(*) basis set, which stands for the standard $4-21 \mathrm{G}$ basis set of Pulay et al. ${ }^{18}$ with a single $\mathrm{d}$ polarization function added on all heteroatoms as well as on hydrogen atoms involved in protonation and/or hydrogen bonding. (An early example of the use of such mixed basis sets in geometry optimizations can be found in the work of Pang et al. ${ }^{19}$ on the structure of some nitrogen heteroaromatics.) The exponents for these extra functions were taken from Dunning's cc-pVDZ (correlation consistent polarized valence double- $\zeta$ ) basis set. ${ }^{20 a}$

Using the B3LYP/4-21G(*) reference geometries, single-point calculations of the energetics were carried out at the B3LYP level with the following larger basis sets: (a) cc-pVDZ, which is of $[3 \mathrm{~s} 2 \mathrm{p} 1 \mathrm{~d} / 2 \mathrm{~s} 1 \mathrm{p}]$ quality; (b) the larger cc-pVTZ (correlation consistent polarized valence triple- $\zeta$ ) basis set, which is of [4s3p2d1f/3s2p1d] quality; (c, d) the aug-cc-pVDZ and augcc-pVTZ (augmented correlation consistent polarized valence double- and triple- $\zeta$, respectively) basis sets of Kendall et al., ${ }^{20 b}$ which differ from the parent cc-pVnZ basis sets by the addition of one low-exponent ("diffuse") function of each angular momentum present. The latter were developed with improved performance for electron affinities in mind, but the diffuse functions were previously (e.g., ref 21) found to be essential in obtaining high-accuracy proton affinities as well (because protonation generally involves a change in the number of free electron pairs). The aug-cc-pVDZ and aug-cc-pVTZ basis sets (AVDZ and AVTZ for short) are of [4s3p2d/3s $2 p]$ and [5s $4 \mathrm{p} 3 \mathrm{~d} 2 \mathrm{f} / 4 \mathrm{~s} 3 \mathrm{p} 2 \mathrm{~d}]$ quality, respectively.

In addition, we considered improvement of the B3LYP/4$21 \mathrm{G}(*)$ energetics with a BSSE (basis set superposition error) correction according to the Boys-Bernardi counterpoise method. ${ }^{23}$

Zero-point energies and RRHO (rigid rotor-harmonic oscillator) thermal corrections at $298 \mathrm{~K}$ were computed from the unscaled B3LYP/4-21G(*) harmonic frequencies. The latter were also essential to verify that some of the structures obtained for the floppier molecules were in fact local minima.

Total energies and zero-point energies are given as Supporting Information. Binding energies, i.e., differences in energy between the dissociation products and the reactant, including the zero-point energies are given in Table 1. Table 2 presents calculated and experimental thermochemical data. The procedure used by Yamabe et al. ${ }^{22}$ was followed to calculate proton affinities as

$$
-\mathrm{PA}=\Delta E+\Delta E_{\mathrm{vib}}+\mathrm{BSSE}+(-5 / 2) R T
$$

$(-5 / 2) \mathrm{RT}$ is the thermal correction of translation and rotation. For the B3LYP/4-21G(*) thermochemical data, estimated BSSE corrections according to the Boys-Bernardi counterpoise method $^{23}$ were also considered.

Atomic polarizability tensor (APT) population analysis ${ }^{24 a}$ was carried out for these structures using the program GAR2PED ${ }^{24 \mathrm{~b}}$ as in our previous work. ${ }^{11}$ For a recent comparative study of the performance of DFT methods for different charge distributions, see ref $24 \mathrm{c}$.

The geometries for the structures that were characterized as local minima are given in Figures $1-4$, together with APT charges for the atoms directly involved in protonation.

\section{Results and Discussion}

1. Proton Affinities of the Smaller Species. Comparison of computed B3LYP/4-21G(*) PAs with experiment for these species reveals that the calculated values leave a lot to be desired. BSSE corrections are found to be very sizable, reaching $15.7 \mathrm{kcal} / \mathrm{mol}$ for $\mathrm{Gl}_{2} \mathrm{H}^{+}$and $8.1 \mathrm{kcal} / \mathrm{mol}$ for $\mathrm{CH}_{3} \mathrm{OH}$. After BSSE correction, the values are still systematically too high. Moreover, the calculated-observed gap is anything but constant or systematic, strongly suggesting that the B3LYP/4-21G(*) level of theory, even with counterpoise correction, is simply inadequate. 
TABLE 2: Comparison of Calculated and Observed Reaction Enthalpies (kcal/mol) at 298 K. Estimates of BSSE by the Counterpoise Method, Where Available, Are Given in Parentheses

\begin{tabular}{|c|c|c|c|c|c|c|}
\hline reaction & B3LYP/4-21G(*) & B3LYP/VDZ & B3LYP/VTZ & B3LYP/AVDZ & B3LYP/AVTZ & experiment \\
\hline $\mathrm{CH}_{3} \mathrm{OH}_{2}^{+} \rightarrow \mathrm{CH}_{3} \mathrm{OH}+\mathrm{H}^{+}$ & $\begin{array}{r}193.84 \\
(8.1)\end{array}$ & $\begin{array}{r}184.16 \\
(3.75)\end{array}$ & $\begin{array}{c}182.25 \\
(1.20)\end{array}$ & $\begin{array}{c}179.11 \\
(0.25)\end{array}$ & $\begin{array}{r}180.32 \\
(0.08)\end{array}$ & $181.9^{c}$ \\
\hline $\mathrm{NH}_{4}^{+} \rightarrow \mathrm{NH}_{3}+\mathrm{H}^{+}$ & $\begin{array}{r}218.06 \\
(5.4)\end{array}$ & $\begin{array}{r}208.72 \\
(3.96)\end{array}$ & $\begin{array}{r}205.78 \\
(1.49)\end{array}$ & $\begin{array}{r}202.24 \\
(0.47)\end{array}$ & $\begin{array}{r}203.39 \\
(0.07)\end{array}$ & $\begin{array}{l}204^{c} \\
203.5^{d}\end{array}$ \\
\hline $\mathrm{NH}_{3} \mathrm{CH}_{3}{ }^{+} \rightarrow \mathrm{NH}_{2} \mathrm{CH}_{3}+\mathrm{H}^{+}$ & $\begin{array}{r}226.85 \\
(5.2)\end{array}$ & $\begin{array}{r}218.32 \\
(2.13)\end{array}$ & $\begin{array}{r}216.56 \\
(0.85)\end{array}$ & $\begin{array}{r}213.86 \\
(0.62)\end{array}$ & $\begin{array}{r}214.86 \\
(0.07)\end{array}$ & $\begin{array}{l}214.1^{c}, \\
215.4^{d}\end{array}$ \\
\hline $\mathrm{NH}_{2}\left(\mathrm{CH}_{3}\right)_{2}{ }^{+} \rightarrow \mathrm{NH}\left(\mathrm{CH}_{3}\right)_{2}+\mathrm{H}^{+}$ & $\begin{array}{r}231.66 \\
(3.5)\end{array}$ & $\begin{array}{r}223.96 \\
(3.05)\end{array}$ & $\begin{array}{r}223.16 \\
(1.13)\end{array}$ & $\begin{array}{r}221.04 \\
(0.40)\end{array}$ & $\begin{array}{r}221.97 \\
(0.14)\end{array}$ & $\begin{array}{l}220.6^{c} \\
222.5^{d}\end{array}$ \\
\hline $\mathrm{N}\left(\mathrm{CH}_{3}\right)_{3} \mathrm{H}^{+} \rightarrow \mathrm{N}\left(\mathrm{CH}_{3}\right)_{3}+\mathrm{H}^{+}$ & $\begin{array}{r}236.14 \\
(4.5)\end{array}$ & $\begin{array}{r}227.00 \\
(2.46)\end{array}$ & $\begin{array}{r}226.98 \\
(0.92)\end{array}$ & $\begin{array}{r}225.28 \\
(0.46)\end{array}$ & $\begin{array}{r}226.12 \\
(0.16)\end{array}$ & $225.1^{c}$ \\
\hline $\mathrm{GlH}^{+} \rightarrow \mathrm{Gl}+\mathrm{H}^{+}$ & $\begin{array}{r}222.58 \\
(8.7)\end{array}$ & $\begin{array}{r}207.36 \\
(2.56)\end{array}$ & $\begin{array}{c}205.73 \\
(0.58)\end{array}$ & $\begin{array}{r}203.64 \\
(0.33)\end{array}$ & {$[204.7]^{g}$} & $\begin{array}{l}204.9^{c}, \\
208.9^{e}\end{array}$ \\
\hline$(\mathrm{Gl})_{2} \mathrm{H}^{+} \rightarrow 2 \mathrm{Gl}+\mathrm{H}^{+}$ & $\begin{array}{c}256.66 \\
(16.8)\end{array}$ & 234.2 & & 227.0 & {$[227.9]^{g}$} & $236^{e}$ \\
\hline $12 \mathrm{c} 4 \mathrm{H}^{+} \rightarrow 12 \mathrm{c} 4+\mathrm{H}^{+}$ & $\begin{array}{r}231.08 \\
(8.4)\end{array}$ & 218.6 & 218.3 & 217.0 & {$[217.9]^{g}$} & $\begin{array}{l}219.6^{a}, \\
221.0^{b} \\
225.0^{e}\end{array}$ \\
\hline $12 \mathrm{c} 4 \mathrm{H}^{+} \cdot \mathrm{CH}_{3} \mathrm{OH} \rightarrow 12 \mathrm{c} 4 \mathrm{H}^{+}+\mathrm{CH}_{3} \mathrm{OH}$ & $\begin{array}{l}35.78 \\
(11.6)\end{array}$ & 27.2 & & 20.0 & & $19.5^{f}$ \\
\hline $12 \mathrm{c} 4 \mathrm{H}^{+} \cdot \mathrm{CH}_{3} \mathrm{OH} \rightarrow 12 \mathrm{c} 4+\mathrm{CH}_{3} \mathrm{OH}_{2}{ }^{+}$ & $\begin{array}{l}73.02 \\
(18.4)\end{array}$ & 61.6 & & 57.9 & & $58.3^{f}$ \\
\hline
\end{tabular}

${ }^{a} \operatorname{Ref} 6 .{ }^{b} \operatorname{Ref} 36 .{ }^{c} \operatorname{Ref} 37 .{ }^{d} \operatorname{Ref} 35 .{ }^{e} \operatorname{Ref} 28 .{ }^{f} \operatorname{Ref} 10 .{ }^{g}$ Extrapolated values using eq 2.

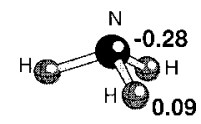

(1)

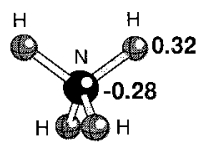

(2)

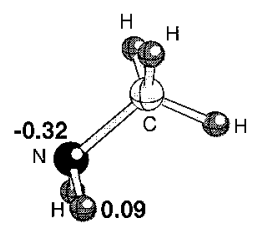

(3)

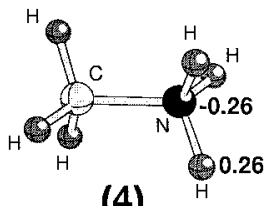

(4)

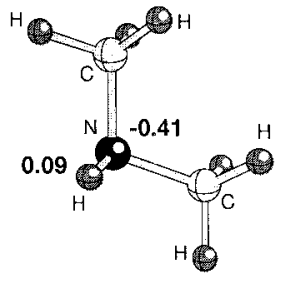

(5)

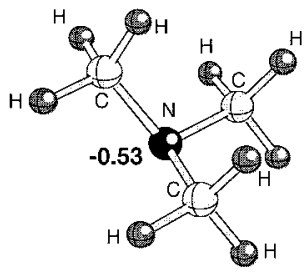

(7)

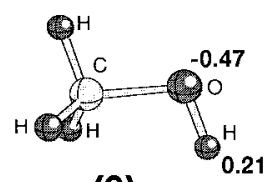

(9)

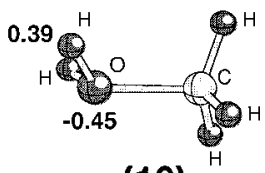

(10)

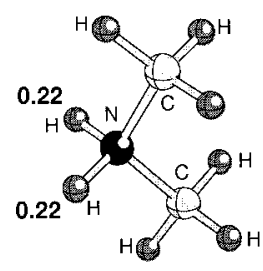

(6)

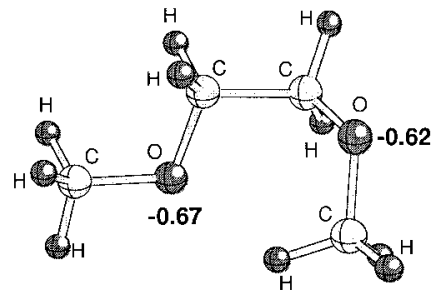

(11)

Figure 1. B3LYP/4-21G(*) computed structures of the species 1-11 as well as hydrogen bond distances $(\AA)$ and APT atomic charges of some relevant atoms.

Using a cc-pVDZ basis set instead appears to improve results somewhat. The calculated-observed difference now however displays a clear trend of increasing with increasing basicity. Switching to the AVDZ basis set remedies this problem: all computed PAs are now systematically slightly too low. Our explanation is that with increasing PA and thus increasing "anionlike" character of the proton acceptor atom in the neutral species diffuse functions afford an increasingly larger stabilization to the neutral. Hence their absence would result in a progressively larger artificial increase of the PA (because the basis set is progressively more biased against the neutral) with increasing basicity, as observed. 


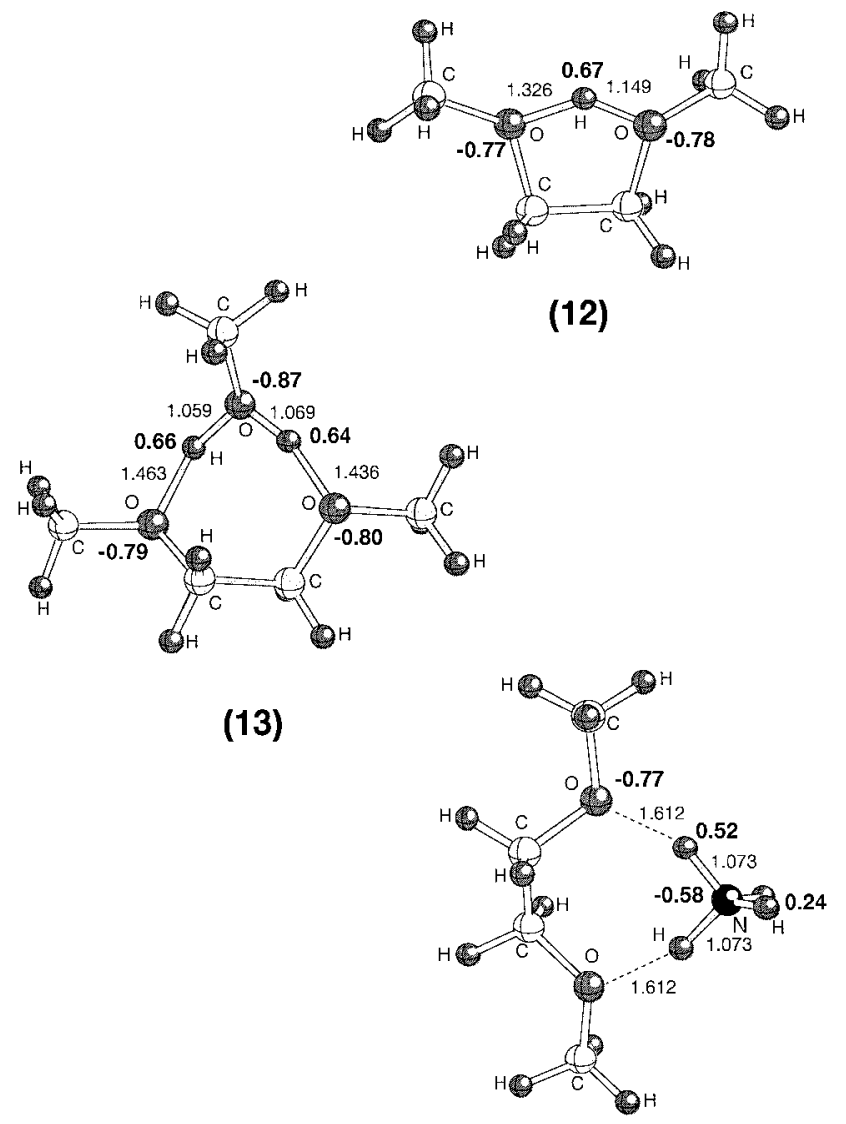

(14)

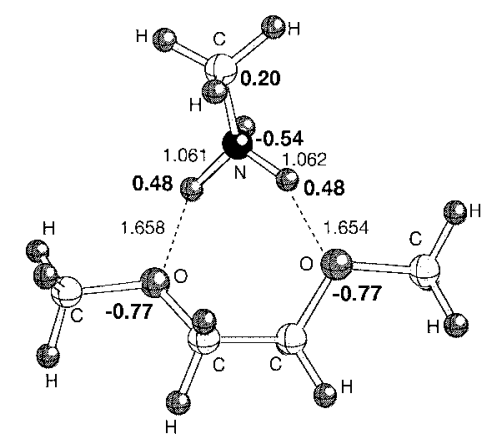

(15)

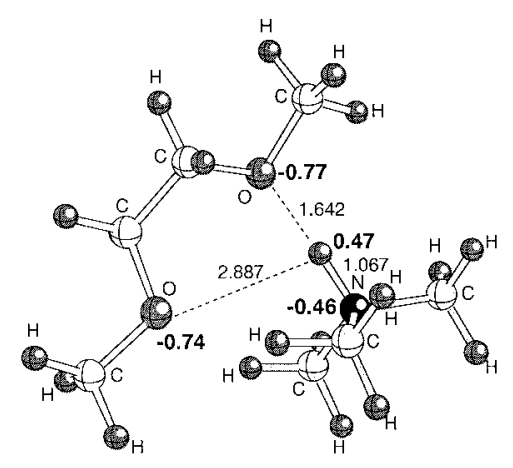

(17)

Figure 2. B3LYP/4-21G(*) computed structures of the species 12-17 as well as hydrogen bond distances ( $\mathrm{A}$ ) and APT atomic charges of some relevant atoms.

As expected, the VTZ results are significantly better than the VDZ results, but still exhibit a greater-than-unity slope for a regression of computed versus observed values. The effect is however much milder because the outermost primitives of the cc-pVTZ basis set are considerably more "diffuse" than those in the cc-pVDZ basis set. As expected, this tendency disappears upon switching to the AVTZ basis set, the B3LYP/AVTZ values being consistently close to the experimental ones. The difference between B3LYP/AVDZ and B3LYP/AVTZ values is however quite small and definitely out of all proportion with the great increase in computational expense involved. (The AVDZ basis set involves 20 basis functions per first-row atom and 9 per hydrogen, compared to 46 and 20, respectively, for AVTZ.) Moreover, for the five proton affinities we have here, a linear regression (in $\mathrm{kcal} / \mathrm{mol}$ )

$$
\mathrm{PA}[\mathrm{AVTZ}]=0.9922(16) \mathrm{PA}[\mathrm{AVDZ}]+2.64(34)
$$

has a correlation coefficient $R=0.99999$ and residuals of 0.08 $\mathrm{kcal} / \mathrm{mol}$ or less. Hence we propose to simply use this equation to somewhat further improve on the computed B3LYP/AVDZ results for the bigger species.

A critical reader would rightly argue that the excellent agreement with experiment at the B3LYP/AVDZ and particularly B3LYP/AVTZ level might be a result of error compensation involving neglect of BSSE. To address this point, we have computed counterpoise $(\mathrm{CP})$ corrections using the larger basis sets, wherever our computational resources permitted us doing so. (These corrections can likewise be found in Table 2.) We see here that the CP corrections are smaller with the cc-pVDZ than with the $4-21 \mathrm{G}(*)$ basis set; the most conspicuous feature, however, is that adding on diffuse functions to obtain the AVDZ basis set reduces the estimated BSSE by almost an order of magnitude. Indeed, ranging from 0.25 to $0.62 \mathrm{kcal} / \mathrm{mol}$ for the systems surveyed, they are appreciably smaller than those with the larger cc-pVTZ basis set $(0.58-1.49 \mathrm{kcal} / \mathrm{mol})$; those with the AVTZ basis set, at $0.07-0.16 \mathrm{kcal} / \mathrm{mol}$, can definitely be called negligible in the context of the present work. In other words, the improvement in agreement with experiment is clearly paralleled by a strong reduction in the estimated BSSE.

A similar phenomenon was observed in a recent ab initio convergence study ${ }^{23 b}$ on the water dimer interaction energy, where adding diffuse functions to a $[5 \mathrm{~s} 4 \mathrm{p} 3 \mathrm{~d} 2 \mathrm{f} 1 \mathrm{~g} / 4 \mathrm{~s} 3 \mathrm{p} 2 \mathrm{~d} 1 \mathrm{f}]$ basis set was found to reduce the CP correction to it by an order of magnitude at the SCF level and still by a factor of 4 at the $\operatorname{CCSD}(\mathrm{T})$ coupled cluster level. Likewise, in a recent calibration study $^{23 \mathrm{c}}$ on the anharmonic force field of acetylene, an unphysical anharmonicity and grossly underestimated harmonic frequency with basis sets as large as $[5 \mathrm{~s} 4 \mathrm{p} 3 \mathrm{~d} 2 \mathrm{f} 1 \mathrm{~g} / 4 \mathrm{~s} 3 \mathrm{p} 2 \mathrm{~d} 1 \mathrm{f}]$ were found to disappear completely upon adding diffuse functions to the basis set: exploratory calculations led to a tentative diagnosis of the problem as dynamical BSSE.

2. Glyme and Related Complexes. The structure of dimethoxyethane (DME, dimethyl glycol ether, "glyme"), Gl (11), has been investigated extensively theoretically and experimentally in the past decade. ${ }^{25 a-d, 26 a-h}$ Analyses of infrared and Raman spectra showed that the $\mathrm{CH}_{2}-\mathrm{CH}_{2}$ bond is gauche in the crystal mixture, ${ }^{25 \mathrm{a}}$ and the $t t t$ (trans-trans-trans) and $t g t$ (trans-gauche-trans) rotamers were found in the liquid and gas phases. ${ }^{25 b-e}$ Astrup reported from electron diffraction measure- 


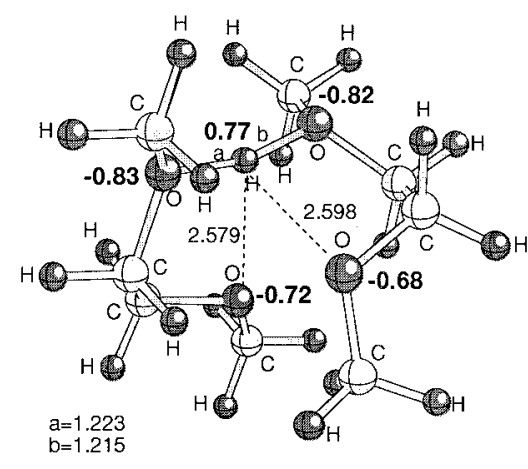

(18)

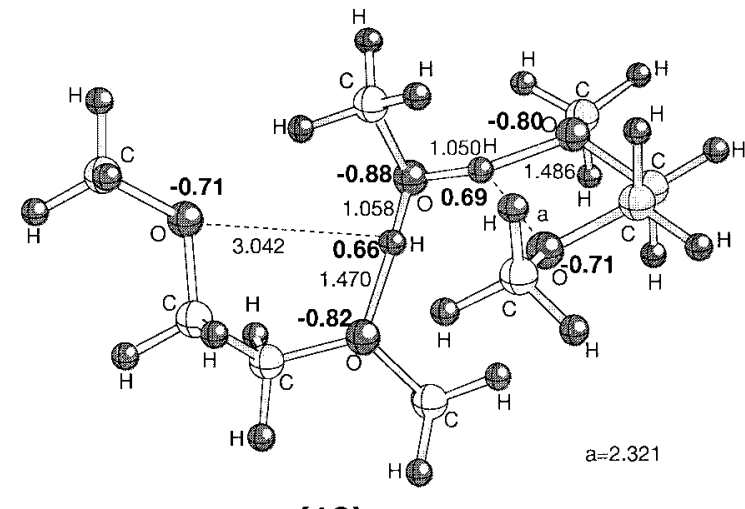

(19)
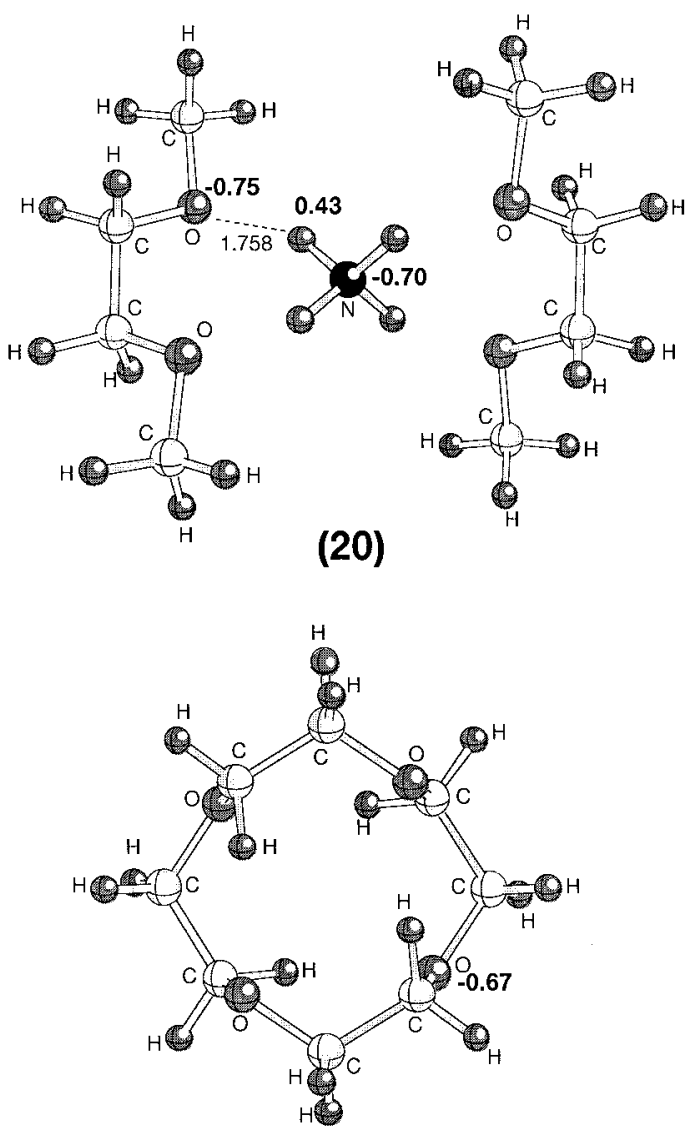

(21)

Figure 3. B3LYP/4-21G(*) computed structures of the species 18-21 as well as hydrogen bond distances ( $\mathrm{A})$ and APT atomic charges of some relevant atoms.

ments that several rotamers exist in the gas phase. ${ }^{26 f}$ Jaffe et al. ${ }^{26 \mathrm{~g}}$ investigated the dependence of the conformational energies of the 10 unique rotamers of DME on the basis set and the level of electron correlation treatment. They found the $t t t$ conformer (which has $C_{2 h}$ symmetry) to be the global minimum and tgt (which has $C_{2}$ symmetry) to be the next lowest conformer. However, introduction of electron correlation strongly reduces the conformational energy difference $\Delta E_{\mathrm{ttt}, \mathrm{tg}}$, as does improving the basis set at the correlated level, resulting in a $\Delta E_{\mathrm{ttt}, \mathrm{tgt}}$ of only $0.10 \mathrm{kcal} / \mathrm{mol}$ as their best estimate. Feller and co-workers, ${ }^{26 \mathrm{~h}}$ using geometric basis set extrapolation techniques $^{26 \mathrm{k}}$ in conjunction with basis sets of up to spdfg quality, found a similarly small value as their best estimate.

The $t g^{+} g^{-}$conformer ( $C_{1}$ symmetry) was found by Jaffe et al. to be the third lowest in energy $(\Delta E=0.23 \mathrm{kcal} / \mathrm{mol}$, agreeing to within $0.1 \mathrm{kcal} / \mathrm{mol}$ with recent measurements ${ }^{261}$ ). Since it however is 4-fold "degenerate" in rotamer space, it was predicted by them to have the highest relative abundance at 0 ${ }^{\circ} \mathrm{C}$, followed by $\operatorname{tgt}$ (which is 2 -fold "degenerate") and $t t t$ (which is not "degenerate"): their computed rotamer populations were in very good agreement with those obtained by Astrup ${ }^{26 f}$ from electron diffraction experiments. ${ }^{26 f}$ (For comparison, recently Brickmann et al. ${ }^{26 j}$ have shown that for 1,2-ethanediol (glycol), at the MP2 level using basis sets up to $6-311+\mathrm{G}(3 \mathrm{df}, 3 \mathrm{pd})$, the conformations where the oxygen atoms are gauche to each other are preferred over the others by at least $2 \mathrm{kcal} / \mathrm{mol}$.) $\mathrm{Abe}^{27}$ has claimed that the gauche preference for the $\mathrm{OC}-\mathrm{CO}$ bond is not a feature caused by the surrounding solvent molecules in solution.
In this work, a rotamer search around the five single bonds was first performed with the PM3 semiempirical method. This method is clearly not sufficient, yielding $t t t$ as the least favorable structure and $\mathrm{tg}^{+} g^{-}<t g t<g^{+} t g^{-}$as the lowest three conformers. (Jaffe et al. found $g^{+} t g^{-}$as the fourth highest rotamer.) At the B3LYP/4-21G(*) level, this ordering changes to $\operatorname{tg}^{+} g^{-}<t t t<t g t<g^{+} \operatorname{tg}^{-}$: improving the basis set to $\mathrm{cc}-$ pVDZ brings the bottom three conformers much closer to each other and strongly increases the separation from the $g^{+} t g^{-}$ rotamer. Further improving the basis set to AVDZ or cc-pVTZ leads to the same $t t t<t g t<t g^{+} g^{-}$energy ordering as found by Jaffe et al., although it appears that B3LYP overestimates the $t t t-t g t$ and $t t t-t g^{+} g^{-}$separations. Reoptimization of the geometries at the B3LYP/AVDZ level does not affect these conclusions.

Since it appears to be clear from both refs $26 \mathrm{~g}$ and $26 \mathrm{~h}$, however, that the $\mathrm{tg}^{+} \mathrm{g}^{-}$conformer 11-fortuitously found as the lowest energy at the B3LYP/4-21G(*) level-will be the most abundant one in practice, we have used it as the reference structure for the proton affinity calculations.

Protonated glyme $\left(\mathrm{Gl} \cdot \mathrm{H}^{+}, \mathbf{1 2}\right)$, on the other hand, is seen to favor a tgt rotamer, which permits bonding of the proton to both oxygens, thus forming a five-membered ring. (For a similar small ion, $\mathrm{Li}^{+}$, it was previously found ${ }^{26 \mathrm{~h}, \mathrm{~m}}$ that tgt is likewise strongly preferred.) The central proton in $\mathbf{1 2}$ is 1.149 and $1.326 \AA$ removed, respectively, from the two oxygens and the methyl groups are almost trans $\left(150^{\circ}\right)$ to the methylene groups. At the B3LYP/4-21G(*) level, this structure is 0.05 $\mathrm{kcal} / \mathrm{mol}$ lower in energy than the $C_{2}$ symmetric structure, where 


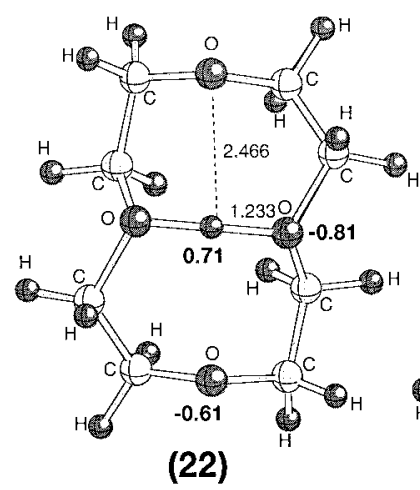

(22)

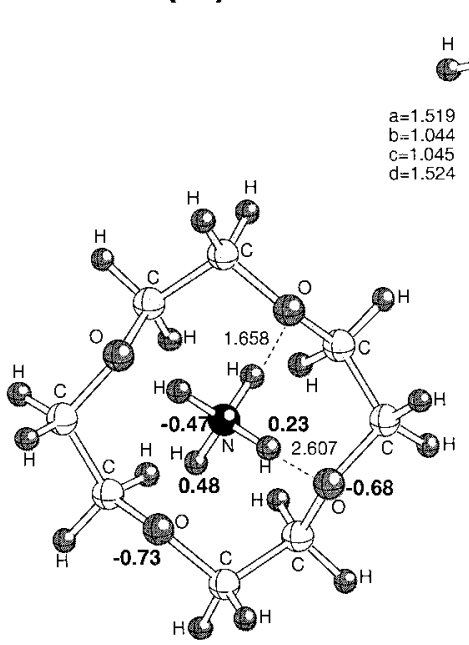

(24)
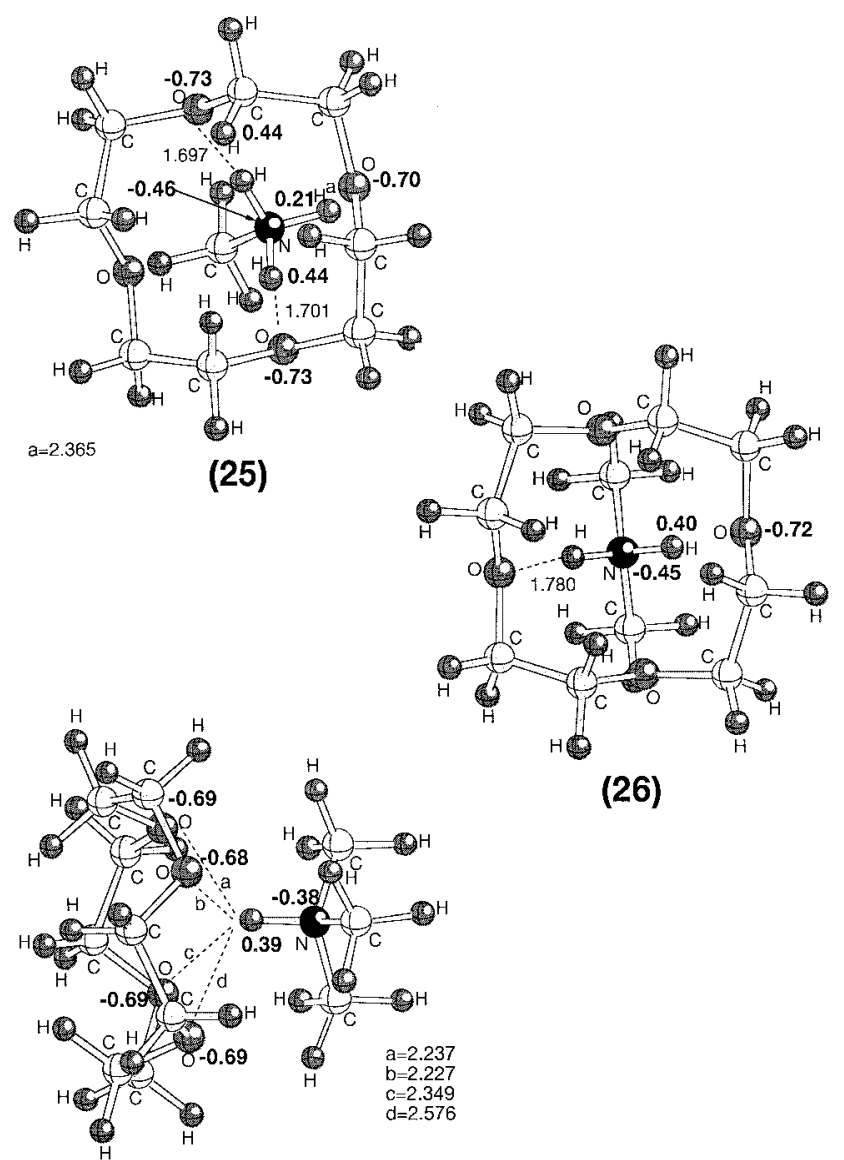

(27)

Figure 4. B3LYP/4-21G(*) computed structures of the species 22-27 as well as hydrogen bond distances $(\AA)$ and APT atomic charges of some relevant atoms.

the proton would be $1.231 \AA$ away from the oxygens. The small barrier may well be a methodological artifact, and in practice, the effective geometry of the species will probably be symmetric, given such a low barrier. The asymmetry between the two $\mathrm{OH}$ distances is however much less pronounced than in the small basis set Hartree-Fock calculations of Meot-Ner et al. ${ }^{28}$ and Yamabe et al.; ${ }^{22}$ a similar phenomenon was noted in ref 11. Overall, the structure fairly closely resembles the suggestion in Figure 5 of the experimental work of Vaidyanathan and Garvey. ${ }^{29}$

In $\mathrm{Gl} \cdot \mathrm{CH}_{3} \mathrm{OH}_{2}{ }^{+}(\mathbf{1 3})$, although in the initial geometry one of the bridge $\mathrm{H}$ atoms is close to glyme, in the optimized geometry both $\mathrm{H}$ atoms are close to methanol and 1.463 and $1.436 \AA$ away from the $\mathrm{O}$ atoms of glyme. Although the proton affinity of glyme $(\mathrm{PA}=204.9 \mathrm{kcal} / \mathrm{mol})$ is higher than that of methanol $(\mathrm{PA}=181.9 \mathrm{kcal} / \mathrm{mol})$, it may be that this quasi symmetric geometry is preferred over a nonsymmetric structure that would occur otherwise. Meot-Ner explains the same type of behavior in the complex of $\mathrm{H}_{3} \mathrm{O}^{+}$with polyethers where the proton is associated with the $\mathrm{H}_{3} \mathrm{O}^{+}$moiety, although the ether groups have higher proton affinities due to the opposing attractions of the ligand groups. ${ }^{28}$

In $\mathrm{Gl} \cdot \mathrm{NH}_{4}{ }^{+}(\mathbf{1 4}), \mathrm{NH}_{3}$ and glyme have equal proton affinities, but it is $\mathrm{NH}_{3}$ that attracts the common proton toward itself. The bridges between $\mathrm{NH}_{4}{ }^{+}$and glyme have $\mathrm{O} \cdots \mathrm{H}$ bonds of 1.612 $\AA$ and $\mathrm{H} \cdots \mathrm{N}$ bonds of $1.073 \AA$. The protons of the bridge bear the most positive charge (0.52), and the oxygens of glyme have the most negative charge $(-0.77)$.

$\mathrm{Gl} \cdot \mathrm{NH}_{3} \mathrm{CH}_{3}{ }^{+}$(15) is quite similar to (14) although not symmetric. Again the bridge protons are the most positive
(0.48) centers and the oxygens are the most negative sites $(-0.77)$. Notice also that $\mathrm{O} \cdots \mathrm{H}$ bonds are longer than in $\mathbf{1 4}$ by $0.04 \AA$.

$\mathrm{Gl} \cdot \mathrm{NH}_{2}\left(\mathrm{CH}_{3}\right)_{2}{ }^{+}(\mathbf{1 6})$ and $\mathrm{Gl} \cdot \mathrm{NH}\left(\mathrm{CH}_{3}\right)_{3}{ }^{+}$(17) retain the tetrahedral geometry around nitrogen. $\mathrm{Gl} \cdot \mathrm{NH}_{2}\left(\mathrm{CH}_{3}\right)_{2}{ }^{+}(\mathbf{1 6})$ has two $\mathrm{H}$ bonds. Although $\mathrm{Gl} \cdot \mathrm{NH}\left(\mathrm{CH}_{3}\right)_{3}{ }^{+}(\mathbf{1 7})$ is singly hydrogen bonded to one of the glyme oxygens, long-range (2.195 and $2.198 \AA$ ) $\mathrm{O} \cdots \mathrm{HC}$ interactions between the other oxygen and two hydrogens from the two nearest methyl groups appear to stabilize this structure. Mautner ${ }^{5}$ has previously reviewed contributions from $-\mathrm{C}-\mathrm{H}^{\delta+}+. \mathrm{O}-$ bonds with polyethers. The charge on the bridge $\mathrm{H}$ atoms varies from 0.52 in $\mathrm{Gl}^{\circ} \mathrm{NH}_{4}{ }^{+}(\mathbf{1 4})$ to 0.48 in $\mathrm{Gl} \cdot \mathrm{NH}_{3} \mathrm{CH}_{3}{ }^{+}$(15) and 0.44 in $\mathrm{Gl} \cdot \mathrm{NH}_{2}\left(\mathrm{CH}_{3}\right)_{2}{ }^{+}(\mathbf{1 6})$. The charges on the bridge $\mathrm{H}$ atoms diminish as the $\mathrm{NH}_{4}{ }^{+}$group changes into $\mathrm{NH}_{m}\left(\mathrm{CH}_{3}\right)_{n}{ }^{+}(m=1,3 ; n=4-m)$ : electron donation from the methyl groups neutralizes the partial positive charge on the bridge proton.

3. Glyme Dimer and Related Complexes. In $(\mathrm{Gl})_{2} \mathrm{H}^{+}(\mathbf{1 8})$, a proton binds one oxygen of one glyme to another oxygen of another glyme, staggered to the first. $\mathrm{O} \cdots \mathrm{H}$ bond lengths are around 1.215 and $1.223 \AA$. The most negative sites are the oxygens $(-0.82)$ hydrogen bonded to the central proton $(0.77)$. Vaidyanathan and Garvey (Figure 6 in ref 29) suggest the two glymes to be at (almost) right angles, each with one hydrogen bond and one weak ion-dipole interaction. Our computed bond distances, as well as the computed $\mathrm{O}-\mathrm{O}-\mathrm{O}-\mathrm{O}$ dihedral angle of $280^{\circ}$, fundamentally agree with this picture. Contrary to Figure III of Mautner et al., ${ }^{28 a}$ we definitely find the proton to be nearly symmetrically bound to two oxygens rather than predominantly to one. In $(\mathrm{Gl})_{2} \mathrm{CH}_{3} \mathrm{OH}_{2}{ }^{+}(\mathbf{1 9})$, the $\mathrm{O} \cdots \mathrm{H}$ bond 
lengths are extended to 1.470 and $1.486 \AA$. In $\left(\mathrm{Gl}_{2}\right)_{2} \mathrm{NH}_{4}{ }^{+}$(20) the $\mathrm{N} \cdots \mathrm{H}$ bond lengths are $1.758 \AA$. Bond length differences in 19 and 20 may be rationalized in terms of the nature of the electronegative atom in the ligand. In 19 oxygen still has a lone pair capable of assisting the $\mathrm{H}$ by donating its electrons and shortening the $\mathrm{H} \cdots \mathrm{O}$ bond, whereas in $\mathbf{2 0}, \mathrm{N}$ cannot show similar behavior. Structure $\mathbf{2 0}$ has four $\mathrm{O} \cdots \mathrm{H}$ bonds because of the symmetric tetrahedral geometry of $\mathrm{NH}_{4}{ }^{+}$and agrees quite well with the previously suggested structure by Feng and Lifshitz ${ }^{7}$ for $(\mathrm{Gl})_{2} \mathrm{NH}_{4}{ }^{+}$based upon experimental findings only, although some of the other structures suggested intuitively ${ }^{7}$ have to be revised following the present density functional calculations (see coming section).

4. 12-Crown-4 and Related Complexes. It is known ${ }^{30}$ that the crowns can adapt their conformation for optimum complexation of the guest, a consequence of their dynamic flexibilty in solution. There are numerous possible conformations ${ }^{31}$ for the isolated 12-crown-4 molecule (12c4), but in the solid state only a few of these conformations have been observed. ${ }^{32}$ In the $C_{4}$ conformation the four $\mathrm{O}$ atoms form a plane with the $\mathrm{CH}_{2}$ groups on one side. In each $\mathrm{OCH}_{2}-\mathrm{CH}_{2}-$ group one $\mathrm{C}$ is closer to the $\mathrm{O}$ atom plane ("up" position) and the second $\mathrm{C}$ is further from the $\mathrm{O}$ atom plane ("down" position). " $C_{4}$ " is used to describe the group of structures based on an idealized molecule with true $C_{4}$ symmetry. For pseudo- $C_{4}$ symmetry if one goes around the macrocyclic chain from one $\mathrm{O}$ atom, the first carbon is down and the next up, a chiral conformation which repeats in the next three OCC units.

The RHF and MP2 optimized structures of the 12c4 ligand have $S_{4}$ symmetry. ${ }^{26 \mathrm{~h}}$ The OCCO dihedral angle in $12 \mathrm{c} 4$ is $70^{\circ}$, $20^{\circ}$ larger than the same angle in the $\mathrm{Li}^{+}(12 \mathrm{c} 4)$ complex. Both the RHF and MP2 optimized structures of $12 \mathrm{c} 4$ are in excellent agreement with the crystal structure of $12 \mathrm{c} 4$ reported by Growth. ${ }^{32}$ For 12-crown-4 (21), we have found the $S_{4}$ symmetric structure to be $13.91 \mathrm{kcal} / \mathrm{mol}$ lower in energy than its $C_{4}$ counterpart. The bond lengths are $\mathrm{O}-\mathrm{C} 1.480 \AA$ A $\mathrm{C}-\mathrm{C} 1.526$ $\AA$, and $\mathrm{C}-\mathrm{O} 1.469 \AA$.

While $12 \mathrm{c} 4$ is quite floppy, $12 \mathrm{c} 4 \mathrm{H}^{+}(\mathbf{2 2})$ is fixed by an intramolecular hydrogen bond. Structure 22 has $C_{2}$ symmetry with the proton $1.233 \AA$ away from two opposite oxygen atoms. This bond is weaker than the one in $\mathbf{1 8}$ due to ring strain as shown by Wasada et al. ${ }^{33}$

Both in $12 \mathrm{c} 4 \mathrm{H}^{+} \cdot \mathrm{CH}_{3} \mathrm{OH}(\mathbf{2 3})$ and $12 \mathrm{c} 4 \mathrm{H}^{+} \cdot \mathrm{NH}_{3}$ (24) there are two hydrogen bonds between the two opposite oxygens and the active protons of the ligands. In $12 \mathrm{c} 4 \mathrm{H}^{+} \cdot \mathrm{CH}_{3} \mathrm{OH}(\mathbf{2 3}), \mathrm{CH}_{3}-$ $\mathrm{OH}_{2}{ }^{+}$is on top of $12 \mathrm{c} 4$ with two $\mathrm{O} \cdots \mathrm{H}$ bonds of 1.519 and $1.524 \AA$, respectively. In $\mathbf{2 4}, \mathrm{NH}_{4}{ }^{+}$is equidistant from the two opposite oxygens; $12 \mathrm{c} 4 \mathrm{H}^{+} \cdot \mathrm{NH}_{3}$ is completely symmetric, with $\mathrm{O} \cdots \mathrm{H}$ bond lengths of $1.658 \AA$. When the central base is methylamine (25) or dimethylamine (26), the ligand is pushed away from the ring, the $\mathrm{O} \cdots \mathrm{H}$ distances being $\{1.697,1.701 \AA$ \} and $1.780 \AA$, respectively. The lengthening of the $\mathrm{O} \cdots \mathrm{H}$ distance in $12 \mathrm{c} 4 \cdot \mathrm{NH}_{m}\left(\mathrm{CH}_{3}\right)_{n}{ }^{+},(m=1,3 ; n=4-m)$ as $n$ increases is not similar to the situation observed for $\mathrm{Gl} \cdot \mathrm{NH}_{m^{-}}$ $\left(\mathrm{CH}_{3}\right)_{n}{ }^{+},(m=1,3 ; n=4-m)$; it may be that the $12 \mathrm{c} 4$ ring pushes away the ligand $\mathrm{NH}_{m}\left(\mathrm{CH}_{3}\right)_{3}{ }^{+}$as $n$ increases and as the ligand becomes crowded. The structure of $12 \mathrm{c}^{4} \mathrm{H}^{+}\left(\mathrm{CH}_{3}\right)_{3} \mathrm{~N}(27)$ is different from the other clusters of $12 \mathrm{c} 4 \mathrm{H}^{+}$with methylamine derivatives: the proton of $\left(\mathrm{CH}_{3}\right)_{3} \mathrm{NH}$ is at $2.23 \AA$ from two opposite oxygens in $12 \mathrm{c} 4$ and the whole structure is stabilized by these long-range interactions.

$12 \mathrm{c} \mathrm{H}^{+}(\mathbf{2 2})$ has the largest negative charge on the hydrogenbonded oxygens $(-0.81)$, and the central proton is 0.71 . In the other clusters of $12 \mathrm{c} 4$ the charges for the oxygens bonded to the active hydrogens and the ones for the bridge hydrogen themselves are distributed as follows: $-0.76,+0.61$ in $\mathbf{2 3}$; $-0.73,+0.48$ in $\mathbf{2 4} ;-0.73,+0.44$ in $\mathbf{2 5} ;-0.72,+0.40$ in $\mathbf{2 6}$; and $-0.69,+0.39$ in 27 . These findings seem to reflect the fact that the shorter the hydrogen bonds are, the greater is the charge separation.

5. Proton Affinities and Binding Energies. Two experimental PA values exist for Gl. The higher Mautner et al. ${ }^{28 a}$ value of $208.9 \mathrm{kcal} / \mathrm{mol}$ however reflects a PA scale ${ }^{28 \mathrm{~b}}$ that is biased upward by $4 \mathrm{kcal} / \mathrm{mol}$ (see Szulejko and McMahon ${ }^{35}$ for details). After taking this into account, our B3LYP/AVDZ value of $203.6 \mathrm{kcal} / \mathrm{mol}$ and particularly the estimated B3LYP/ AVTZ value of $204.7 \mathrm{kcal} / \mathrm{mol}$ are in excellent agreement with experiment. Our calculations for $12 \mathrm{c} 4$ yield $217.0 \mathrm{kcal} / \mathrm{mol}$ at the B3LYP/AVDZ level or an estimated $217.9 \mathrm{kcal} / \mathrm{mol}$ at the B3LYP/AVTZ level, somewhat below the lowest experimental value, $219.6 \mathrm{kcal} / \mathrm{mol}^{6}$ Given the extremely low harmonic frequencies involved, we assume that the RRHO treatment in the thermal corrections could lead to a substantial error. The error margin in our calculations is not necessarily small enough to enable us to rule out the higher $(221.0 \mathrm{kcal} / \mathrm{mol})$ experimetal value of Sharma et al. ${ }^{36}$

Even after taking into account the $4 \mathrm{kcal} / \mathrm{mol}$ downward shift required for the reported Mautner et al. ${ }^{28}$ value for $\mathrm{Gl}_{2}$, this still leaves a gap of $5 \mathrm{kcal} / \mathrm{mol}$, which is unexpectedly large. The Mautner value implies a much larger association energy for $\mathrm{GlH}^{+}+\mathrm{Gl} \rightarrow \mathrm{Gl}_{2} \mathrm{H}^{+}, 27.4 \mathrm{kcal} / \mathrm{mol}$, than was previously found by Kebarle and co-workers, ${ }^{36} 22.8 \mathrm{kcal} / \mathrm{mol}$. As argued by Mautner et al., ${ }^{28}$ the dimerization energies should be small because internal hydrogen bonds are broken. If we adopt the Kebarle et al. value for the dimerization energy, we obtain 227.2 $\mathrm{kcal} / \mathrm{mol}$, compared to $227.5 \mathrm{kcal} / \mathrm{mol}$ from ref 36 , and not overly different from our own estimated B3LYP/AVTZ value, $225.5 \mathrm{kcal} / \mathrm{mol}$. Again, we suggest that at least part of the remaining discrepancy between theory and experiment would be due to poor RRHO thermal corrections.

As can be seen from Table 2, differences between B3LYP/ $4-21 \mathrm{G}\left({ }^{*}\right)$ and B3LYP/AVDZ energies may be in the $20-30$ $\mathrm{kcal} / \mathrm{mol}$ range. The subsequent discussion will be based exclusively on the B3LYP/AVDZ results, which were seen above to be quite close to experiment at least for the proton affinities. As also seen from Table 2, the computed reaction enthalpies at $298 \mathrm{~K}$ for the two dissociation channels of the $12 \mathrm{c} \mathrm{H}^{+} \cdot \mathrm{CH}_{3} \mathrm{OH}$ complex, 20.0 and $57.9 \mathrm{kcal} / \mathrm{mol}$, agree excellently with the corresponding experimental values ${ }^{4}$ of 19.5 and $58.3 \mathrm{kcal} / \mathrm{mol}$, respectively.

Regarding the dissociation energies of $\mathrm{Gl}^{\cdot} \mathrm{CH}_{3} \mathrm{OH}_{2}{ }^{+}(\mathbf{1 3})$ and of Gl- $\mathrm{NH}_{4}{ }^{+}$(14) to produce $\mathrm{CH}_{3} \mathrm{OH}_{2}{ }^{+}$and $\mathrm{NH}_{4}{ }^{+}$, respectively (Table 2), the trend observed is seen to be based on the $\mathrm{O} \cdots \mathrm{H}$ and $\mathrm{N} \cdots \mathrm{H}$ bond lengths (Figure 1 ) in the compounds considered: the shorter and the stronger the bond, the more energy is needed to break it. The binding energy for reactions II and IV displays the relative strength of the proton affinities of $\mathrm{CH}_{3} \mathrm{OH}$ and $\mathrm{NH}_{3}$ : more energy is released when $\mathrm{NH}_{3}$ is inserted into $\mathrm{GlH}^{+}$. Considering $\mathrm{Gl} \cdot \mathrm{NH}_{3} \mathrm{CH}_{3}{ }^{+}(\mathbf{1 5}), \mathrm{Gl} \cdot \mathrm{NH}_{2}\left(\mathrm{CH}_{3}\right)_{2}{ }^{+}$(16), and $\mathrm{Gl} \cdot \mathrm{NH}\left(\mathrm{CH}_{3}\right)_{3}{ }^{+}(\mathbf{1 7})$ in reactions VII, IX, and XI, it is possible to state that dissociation energies decrease as the number of methyl groups increases. In reaction XI, for Gl$\mathrm{NH}\left(\mathrm{CH}_{3}\right)_{3}{ }^{+}(\mathbf{1 7})$ the binding energy is considerably smaller than for 14,15 , and 16 due to the fact that a single $\mathrm{O} \cdots \mathrm{H}$ bond is broken in $\mathbf{1 7}$ whereas two $\mathrm{O} \cdots \mathrm{H}$ bonds are broken in the others. For reactions VI and VIII insertion of methylamine derivatives is expected to be easier as the proton affinity of the ligand increases. As expected, the energy released in these reactions 
increases as the number of methyl groups increases in methylamines. Reaction $X$ does not follow this trend because of the single $\mathrm{O} \cdots \mathrm{H}$ bond as described previously.

Regarding the binding energies of $\mathbf{1 9}$ and $\mathbf{2 0}$ in reactions XV and XVII (Table 2), the first one refers to the breakage of two $\mathrm{H}$ bonds, whereas the second one refers to the cleavage of four $\mathrm{H}$ bonds. Binding energies per $\mathrm{O} \cdots \mathrm{H}$ and $\mathrm{N} \cdots \mathrm{H}$ bonds amount to 30.8 and $27.7 \mathrm{kcal} / \mathrm{mol}$, respectively; this is in agreement with the expectations based on the shorter $\mathrm{H}$ bonds in $\mathbf{1 9}$ relative to 20. Insertion of $\mathrm{NH}_{3}$ into $(\mathrm{Gl})_{2} \mathrm{H}^{+}$is more exothermic than insertion of $\mathrm{CH}_{3} \mathrm{OH}$ (reactions XVI and XIV).

The binding energies deduced from reactions XIX and XXI show a trend similar to reactions II and IV with almost the same difference of $13 \mathrm{kcal} / \mathrm{mol}$, with ammonia insertion being more exothermic than methanol. For $12 \mathrm{c} 4 \cdot \mathrm{NH}_{m}\left(\mathrm{CH}_{3}\right)_{n}{ }^{+},(m=1,3$; $n=4-m)$ the binding energy decreases as the number of methyl groups in the ligand increases as mentioned earlier for $(\mathrm{Gl})_{2} \mathrm{NH}_{m}\left(\mathrm{CH}_{3}\right)_{n}{ }^{+},(m=1,3 ; n=4-m)$. Comparison of the binding energies deduced for reactions XIV and XIX reflects the stability of $12 \mathrm{c} 4 \mathrm{H}^{+} \cdot \mathrm{CH}_{3} \mathrm{OH}$ with respect to $(\mathrm{Gl})_{2} \mathrm{CH}_{3} \mathrm{OH}_{2}{ }^{+}$; the same is true for reactions XVI and XXI despite the larger number of $\mathrm{H}$ bonds in $\mathbf{2 0}$ than in $\mathbf{2 4}$. There are four $\mathrm{O} \cdots \mathrm{H}$ bonds in $\mathbf{2 0}$ and only two $\mathrm{O} \cdot \boldsymbol{*} \mathrm{H}$ bonds in $\mathbf{2 4}$, and the ratio of the binding energies per hydrogen bond for reactions XVI and XXI is larger than that for reactions XIV and XIX, where the number of $\mathrm{O} \cdots \mathrm{H}$ bonds is the same. It can be concluded that ammonia/methanol insertion into $12 \mathrm{c} 4 \mathrm{H}^{+}$relative to $(\mathrm{Gl})_{2} \mathrm{H}^{+}$ is more exothermic per hydrogen bond for the former than for the latter. These findings are in agreement with the experimental observations of Feng and Lifshitz, ${ }^{7}$ where ammonia insertion into $12 \mathrm{c} \mathrm{H}^{+}$was found to be 1 order of magnitude more efficient than its insertion into $(\mathrm{Gl})_{2} \mathrm{H}^{+}$; the same protonated species were found to be equally efficient toward methanol.

Experimental work on protonated complexes containing ligands with a total of four polar groups has shown increasing binding energies with increasing flexibility of the ligands, ${ }^{26}$ and this behavior was attributed to the stabilization of the proton by the free ether groups. The same is true for reactions XVIII and XII, where the calculated binding energy for $(\mathrm{Gl})_{2} \mathrm{H}^{+}$is higher than the one for $12 \mathrm{c} 4 \mathrm{H}^{+}$.

Agreement between computed RRHO entropies and available experimental values is quite poor due to the limitations inherent in RRHO theory for the present systems, and we have not pursued this point further.

\section{Conclusions}

We draw a number of conclusions from this study.

The geometric features of the optimized clusters with B3LYP/ 4-21G(*) agree with experimental findings (where available) and with a priori expectations.

The B3LYP/aug-cc-pVDZ//B3LYP/4-21G(*) level of theory is found to be a particularly good compromise between CPU time and quality of results for proton affinities (and related reaction energies) of medium-sized molecules. Reaction enthalpies for the protonated clusters at this level of theory are in very good agreement with experimental data where the latter are available. The "diffuse" part of the aug-cc-pVDZ basis set is found to be more essential than extension of the underlying basis set from cc-pVDZ to cc-pVTZ. The great improvement in agreement between B3LYP and experimental proton affinities upon adding diffuse functions to the basis set is directly related to a drastic reduction in the counterpoise-estimated basis set superposition error.
Insertion of $\mathrm{NH}_{3}$ into $\mathrm{GlH}^{+},(\mathrm{Gl})_{2} \mathrm{H}^{+}$and $12 \mathrm{c} 4 \mathrm{H}^{+}$is more exothermic than insertion of $\mathrm{CH}_{3} \mathrm{OH}$ into the same protonated species.

Dissociation energies to produce the protonated bases reflect the strength of the $\mathrm{O} \cdots \mathrm{H}$ bonds: more energy is required to break $\mathrm{O} \cdots \mathrm{H}$ bonds when the base is methanol rather than ammonia and methylamine(s).

Insertion of $\mathrm{NH}_{3}$ into $12 \mathrm{c} 4 \mathrm{H}^{+}$is more exothermic than its insertion into $(\mathrm{Gl})_{2} \mathrm{H}^{+}$; the exothermicity for the insertion of $\mathrm{CH}_{3} \mathrm{OH}$ is comparable for $12 \mathrm{c} 4 \mathrm{H}^{+}$and $(\mathrm{Gl})_{2} \mathrm{H}^{+}$.

Acknowledgment. D.A. and V.A. acknowledge the support from the Bogaziçi University Research Funds. J.M. is a Yigal Allon Fellow and an Honorary Research Associate ("Onderzoeksleider in Eremandaat") of the National Science Foundation of Belgium. The authors thank Mr. Olivier Uzan and Mrs. Miriam Ahituv for their assistance with the figures and Drs. David Feller and Richard L. Jaffe for critical reading of the manuscript prior to publication. This research was supported by The Israel Science Foundation founded by the Israel Academy of Sciences and Humanities. The Farkas Research Center is supported by the Minerva Gesellschaft für die Forschung $\mathrm{GmbH}$, München.

Supporting Information Available: Table of total energies and zero-point energies (1 page). Ordering information is given on any current masthead page.

\section{References and Notes}

(1) Pedersen, C. J. J. Am. Chem. Soc. 1967, 89, 7017.

(2) (a) Lehn, J. M. Acc. Chem. Res. 1978, 11, 49. (b) More, M. B.; Ray, D.; Armentrout, P. B.; J. Phys. Chem. A 1997, 101, 831, 4254, 7007.

(3) Meot-Ner (Mautner), M. J. Am. Chem Soc. 1983, 105, 4912.

(4) Sharma, R. B.; Kebarle, P. J. Am. Chem. Soc. 1984, 106, 3913.

(5) Meot-Ner (Mautner), M. Acc. Chem. Res. 1984, 17, 186.

(6) Meot-Ner (Mautner), M. J. Am. Chem Soc. 1983, 105, 4906

(7) Feng, W. Y.; Lifshitz, C. J. Am. Chem. Soc. 1995, 117, 11548.

(8) Feng, W. Y.; Goldenberg, M.; Lifshitz, C. J. Am. Soc. Mass. Spectrom. 1994, 5, 695.

(9) Feng, W. Y.; Lifshitz, C. Int. J. Mass. Spectrom. Ion Processes 1995, 149/150, 13.

(10) Feng, W. Y.; Ling, Y.; Lifshitz, C. J. Phys. Chem. 1996, 100, 35.

(11) Martin, J. M. L.; Aviyente, V.; Lifshitz, C. J. Phys. Chem. 1997, 101, 2597.

(12) Frisch, M. J.; Trucks, G. W.; Schlegel, H. B.; Gill, P. M. W.; Johnson, B. G.; Robb.; M. A.; Cheesman, J. R.; Keith, T.; Petersson, G. A.; Montgomery, J. A.; Raghavachari, K.; Al-Laham, M. A.; Zakrzewski, V. G.; Ortiz, J. V.; Foresman, J. B.; Cioslowski, J.; Stefanov, B. B.; Nanayakkara, A.; Challacombe, M.; Peng, C. Y.; Ayala, P. Y.; Chen, W.; Wong, M. W.; Andres, J. L.; Replogle, E. S.; Gomperts, R.; Martin, R. L.; Fox, D. J.; Binkley, J. S.; Defrees, D. J.; Baker, J.; Stewart, J. J. P.; HeadGordon, M.; Gonzales, C.; Pople, J. A. GAUSSIAN 94, Revision C.2; Gaussian Inc.: Pittsburgh, PA, 1995.

(13) Stewart, J. J. P. J. Comput. Chem. 1989, 10, 209, 221.

(14) SPARTAN version 4.0; Wavefunction, Inc.: 18401 Von Karman Ave., \#370 Irvine, CA 92715.

(15) Becke, A. D. J. Chem. Phys. 1993, 98, 5648

(16) Lee, C.; Yang, W.; Parr, R. G. Phys. Rev. 1988, B37, 785.

(17) (a) Devlin, F. J.; Finley, J. W.; Stephens, P. J.; Frisch, M. J. J. Phys. Chem. 1995, 99, 16883. (b) Martin, J. M. L.; El-Yazal, J.; François, J. P. Mol. Phys. 1995, 86, 1437. (c) Rauhut, G.; Pulay, P. J. Phys. Chem. 1995, 99, 3093. (d) Wong, M. W. Chem. Phys. Lett. 1996, 256, 391.

(18) Pulay, P.; Fogarasi, G.; Pang, F.; Boggs, J. E. J. Am. Chem. Soc. 1979, 101, 2550.

(19) Pang, F.; Pulay, P.; Boggs, J. E. J. Mol. Struct. (THEOCHEM) 1982, 88, 79. See also: Martin, J. M. L.; François, J. P.; Gijbels, R. J. Comput. Chem. 1989, 10, 346, for an application to proton affinities.

(20) (a) Dunning, T. H., Jr. J. Chem. Phys. 1989, 90, 1007. (b) Kendall,

R. A.; Dunning, T. H., Jr.; Harrison, R. J. J. Chem. Phys. 1992, 96, 6796.

(21) Martin, J. M. L.; Lee, T. J. Chem. Phys. Lett. 1996, 258, 136.

(22) Yamabe, S.; Hirao, K.; Wasada, H. J. Phys. Chem. 1992, 96, 10261.

(23) (a) Boys, S. F.; Bernardi, F. Mol. Phys. 1970, 19, 553, 22. (b) Halkier, A.; Koch, H.; Jørgensen, P.; Christiansen, O.; Beck Nielsen, I. M.; Helgaker, T. Theor. Chem. Acc. 1997, 97, 150. (c) Martin, J. M. L.; Lee, T. J.; Taylor, P. R. J. Chem. Phys. 1998, 108, 676. 
(24) (a) Cioslowski, J. J. Am. Chem. Soc. 1989, 111, 8333. (b) Martin, J. M. L.; Van Alsenoy, C. GAR2PED; University of Antwerp, 1995. (c) De Proft, F.; Martin, J. M. L.; Geerlings, P. Chem. Phys. Lett. 1996, 250, 393.

(25) (a) Andersson, M.; Karlström, G. J. Phys. Chem. 1990, 94, 4299 (b) Abe, A.; Tasaki, K. J. Mol. Struct. 1986, 145, 309. (c) Barzaghi, M.; Gamba A.; Morosi, G., J. Mol. Struct. 1988, 170, 69. (d) Bressanini, D. Gamba A.; Morosi, G. J. Phys. Chem. 1990, 94, 4299.

(26) (a) Matsuura H.; Miyazawa T., Machida K. Spectrochim. Acta 1973, 29A, 771. (b) Miyake A. J. Am. Chem. Soc. 1960, 82, 3040. (c) Machida, K.; Miyazawa T. Spectrochim. Acta 1964, 20, 1865. (d) Iwamoto R. Spectrochim. Acta 1971, 27A, 2385. (e) Ogawa, Y.; Ohta, M.; Sakakibara, M.; Matsuura H.; Harada, I.; Shimanouchi, T. Bull. Chem. Soc. Jpn. 1977, 50, 650. (f) Astrup, E. E. Acta Chem. Scand. 1979, A33, 655. (g) Jaffe, R. L.; Smith, G. D.; Yoon, D. Y. J. Phys. Chem. 1993, 97, 12745. (h) Ray, D.; Feller, D.; More, M. B.; Glendening, E. D.; Armentrout, P. B. J. Phys. Chem. 1996, 100, 16116. (i) Murcko, M. A.; DiPaola, R. A. J. Am. Chem. Soc. 1992, 114, 10010. (j) Reiling, S.; Brickmann, J.; Schlenkrich, M.; Bopp, P. A. J. Comput. Chem. 1996, 17, 133. (k) Feller, D. J. Chem. Phys. 1992, 96, 6104. (1) Yoshida, H.; Tanaka, T.; Matsuura, H. Chem. Lett. 1996, 8, 637. See also Yoshida, H.; Kaneko, I.; Matsuura, H.; Ogawa, Y.; Tasumi,
M. Chem. Phys. Lett. 1992, 196, 601. (m) Smith, G. D.; Jaffe, R. L.; Partridge, H. J. Phys. Chem. A 1997, 101, 1705.

(27) Inomata, K.; Abe, A. J. Phys. Chem. 1992, 96, 7934.

(28) (a) Meot-Ner, M.; Sieck, L. W.; Scheiner, S.; Duan, X. J. Am. Chem. Soc. 1994, 116, 7848. (b) Mautner (Meot-Ner), M.; Sieck, L. W. J. Am. Chem. Soc. 1991, 113, 4448.

(29) Vaidyanathan, G.; Garvey, J. F. J. Phys. Chem. 1994, 98, 2248

(30) Ratcliffe, C. I.; Buchanan, G. W.; Denike, J. K. J. Am. Chem. Soc. 1995, 117, 2900.

(31) Seidl, E. T.; Schaefer, H. F., III. J. Phys. Chem. 1991, 95, 3589.

(32) Growth, P. Acta Chem. Scand. Ser. A 1981, 35, 463.

(33) Wasada, H.; Tsutsui, Y.; Yamabe, S. J. Phys. Chem. 1996, 100, 7367.

(34) Meot-Ner, M.; Sieck, L. W.; Liebman, J. F.; Scheiner, S. J. Phys. Chem. 1996, 100, 6445.

(35) Szulejko, J. E.; McMahon, T. B. J. Am. Chem. Soc. 1993, 115 7839.

(36) Sharma, R. B.; Blades, A. T.; Kebarle, P. J. J. Am. Chem. Soc. 1984, 106, 510 .

(37) Lias, S. G.; Liebman, J. F.; Levin, R. D. J. Phys. Chem. Ref. Data 1984, 13, 695 . 